\title{
O desenvolvimento como processo de mudança cultural: as conexões entre excedente e estruturas sociais na visão de Celso Furtado
}

Development as a process of cultural change: the connections between surplus and social structures in Celso Furtado's vision

\author{
Renata Bianconi (1) \\ Mauricio C. Coutinho(2) \\ (1) Universidade Federal de São Paulo/ \\ Universidade Estadual de Campinas \\ (2) Universidade Estadual de Campinas
}

\begin{abstract}
The purpose of this article is to present Furtado's vision of surplus and social structure, suggesting that a rereading attentive to these two elements allows a better understanding of his work. For Furtado, surplus is the starting point for a broader apprehension of development, since it gives scope for community choice and processes of social transformation. In his earlier works on development and underdevelopment, he already insisted on how surplus and social structure defined lifestyles and the process of accumulation itself. Furtado's approach to the relations between surplus and social structures acquires new contours in the 1970s, taking on account the transformations in the international economy and peripheral industrialization. The interaction between economic, cultural and political factors provides new contours to the notion of surplus. The article thus provides a review of the uses and significance of the notion of surplus in Furtado's thinking.
\end{abstract}

\section{Keywords}

Celso Furtado, surplus, social structures.

JEL Codes B200, B3.

\section{Resumo}

O objetivo deste artigo é apresentar a visão de Furtado sobre excedente e estrutura social, sugerindo que uma releitura atenta a esses dois elementos permite melhor compreensão de sua obra. Para Furtado, o excedente é o ponto de partida para uma apreensão mais ampla do desenvolvimento, uma vez que possibilita escolha por parte da comunidade e processos de transformação social. Seus primeiros trabalhos sobre desenvolvimento e subdesenvolvimento já insistem na interconexão entre excedente e estrutura social na definição dos modos de vida e do processo de acumulação. Sua abordagem das relações entre excedente e estruturas sociais ganha novos contornos nos anos 1970, levando em conta as transformações na economia internacional e a industrialização periférica. A interação entre pensamento econômico, cultural e político dá novos contornos à noção de excedente. O artigo se detém nos usos e significado da noção de excedente no pensamento de Furtado em seus diversos momentos.

\section{Palavras-chave \\ Celso Furtado, excedente, estruturas sociais.}

Códigos JEL B200, B3. 


\section{Introdução}

No primeiro volume da Obra autobiográfica Furtado $(1985,2014)$ assinala que o ponto de partida para uma apreensão mais ampla do fenômeno do desenvolvimento econômico é a noção de excedente. Acrescenta que já em seu comentário a Nurkse (FURTADO, 1952) havia sustentado que somente a existência de excedente social dá margem a possibilidades de escolha por parte da comunidade e a processos de mudança social. $\mathrm{Na}$ ausência da noção de excedente, seria impossível tratar deste amplo fenômeno de mudança cultural que é o desenvolvimento.

Furtado acrescenta que Paul Baran, partindo de uma base metodológica diversa, chegaria posteriormente a conclusão similar: tomar o excedente como base de uma teoria da mudança econômica. Refere-se à peculiar utilização do excedente para explicar o desenvolvimento econômico e o subdesenvolvimento proposta por Baran em The Political Economy of Growth (BARAN, 1957) ${ }^{1}$. Informa ainda que no ensaio intitulado "O Desenvolvimento Econômico (ensaio de interpretação histórico-analítica)", explicara a importância da noção de excedente econômico, bem como suas origens e desventuras ao longo da evolução do pensamento econômico. Este ensaio, publicado pela primeira vez em 1955 e republicado em 1956, veio a compor Desenvolvimento e Subdesenvolvimento (FURTADO, 1961), obra que reúne os principais estudos sobre desenvolvimento econômico de Furtado dos anos 1950. Na biografia, Furtado conclui afinal que, um quarto de século após, convenceu-se da existência de terreno ainda a explorar nos domínios do excedente. Com este ânimo foi redigido o Prefácio a Nova Economia Politica (FURTADO, 1976a).

A iniciativa de Furtado em retomar a temática do excedente ainda ao início da década de 1950 levou alguns comentadores (TAVARES, 1978; SZMRECSÁNYI, 2003; BOIANOVSKY, 2010) a destacarem o pioneirismo, bem como o paralelismo com Baran, cuja obra gerou uma onda de reflexões sobre o excedente. ${ }^{2}$ Adiante voltaremos a Baran e à eventual compatibilidade com a abordagem de Furtado. De todo modo, assinale-se que

1 Embora menos referida à temática do subdesenvolvimento, a visão de excedente de Baran já está bem definida em Baran (1953). Maria da Conceição Tavares (1978) reconhece que Furtado e Baran foram pioneiros em utilizar a noção de excedente no tratamento do desenvolvimento econômico.

2 Sobre a onda de abordagens e controvérsias a partir da noção de excedente, motivadas por Baran (1953, 1957) e Baran e Sweezy (1966), ver Santarcángelo e Borroni (2012). 
há um longo percurso entre os primeiros tratamentos do excedente por Furtado, do início dos anos 1950, e os definitivos, bem caracterizados na segunda metade dos anos 1970. Nesse intervalo, as interconexões entre excedente econômico e estrutura social aparecem em obras de natureza diversa: de natureza histórica (Formação Econômica do Brasil, 1959); relacionadas à teoria do desenvolvimento (Desenvolvimento e Subdesenvolvimento, 1961; Teoria e Politica do Desenvolvimento Econômico, 1967); explorações do esgotamento do processo de substituição de importações e dos novos rumos da economia após 1960 (Subdesenvolvimento e Estagnação na América Latina, 1966; Análise do "Modelo" Brasileiro, 1972; O Mito do Desenvolvimento Econômico, 1974). No Prefácio a Nova Economia Política (1976), temas que vinham assumindo lugar de destaque nas obras de Furtado desde 1965, como as transformações econômicas do pós-guerra e a dominância das empresas multinacionais, serão retomados por meio de uma redefinição da noção de excedente e de sua interconexão com as estruturas sociais.

Como seria de esperar, a visão de Furtado a respeito do excedente econômico muda no transcorrer do período acima delimitado. Em textos como A Economia Brasileira (1954) e em alguns dos ensaios de Desenvolvimento e Subdesenvolvimento (1961), tratava-se de reconhecer a existência de um fenômeno específico - o subdesenvolvimento - e de estabelecer uma visão histórico-teórica de desenvolvimento econômico, em contraste com diversas abordagens concorrentes; inclusive aquelas que negavam qualquer especificidade ao subdesenvolvimento, ou que não reconheciam no desenvolvimento um fenômeno específico, merecedor de tratamento histórico próprio. Já nos textos dos anos 1970, tratava-se de debater o fracasso de diversos esforços de desenvolvimento, bem como o redesenho do espaço econômico mundial pela via das empresas multinacionais. Mudara o próprio caráter do subdesenvolvimento, e a análise das transformações envolveu uma redefinição da noção de excedente.

Acrescente-se que a apropriação da teoria econômica por Furtado, por ter como elemento central a temática do desenvolvimento econômico, sempre enfatizou o excedente. Em diversos trabalhos seus encontramos sumários da evolução do núcleo conceitual da teoria econômica, dando destaque à noção de excedente. Se uma primeira versão destes sumários aparece já no capítulo VI de A Economia Brasileira, a reexposição da evolução da teoria econômica do Prefácio a Nova Economia Política inicia, não por acaso, pela fisiocracia. Em suma, as incursões à evolução da teoria econômica 
de Furtado sempre tiveram por norte a temática do excedente. Do mesmo modo, os trabalhos de síntese histórica a partir de variáveis econômicas Formação Econômica do Brasil é apenas o caso mais conhecido - apoiam-se largamente no excedente econômico e estruturas sociais associadas.

O objetivo deste artigo é apresentar a visão de Furtado sobre excedente e estrutura social e, simultaneamente, sugerir que uma releitura atenta a esses dois elementos pode permitir uma melhor compreensão de sua obra. Afora a Introdução e as Conclusões, o artigo contém duas seções. A seção dois caracteriza as primeiras abordagens de Furtado ao excedente, e inclui tanto as aproximações iniciais à temática do desenvolvimento, como as bem conhecidas sínteses de processos históricos, em especial as aplicadas ao Brasil. A seção três analisará o papel do excedente na reformulação da visão de Celso Furtado a partir do início dos anos 1970, em particular a recaracterização da dependência como um fenômeno cultural complexo, associado a uma estrutura econômica em mutação. Veremos que a visão de Furtado sobre excedente e subdesenvolvimento, bem como sobre as alternativas abertas aos países subdesenvolvidos face aos impasses da industrialização por substituição de importações, adquirem novos componentes que envolvem a interação entre pensamento econômico, cultural e político.

\section{Excedente e desenvolvimento econômico: primeira aproximação}

Uma primeira versão dos sumários de evolução do pensamento econômico de Furtado aparece no sexto capítulo ("Formulação Teórica do Problema do Crescimento Econômico") de A Economia Brasileira. Na segunda parte do capítulo, intitulada "A Teoria do Desenvolvimento na Ciência Econômica"3, Furtado reavalia a ciência econômica, tendo em vista sua "duplicidade fundamental", ou seu caráter abstrato e histórico, para concluir que ela tendeu a fixar-se em elementos abstratos e supostamente universais da realidade, esquecendo-se do ambiente histórico em que tais elementos adquirem validade e, especialmente, de sua evolução no tempo. A teoria do desenvolvimento econômico, pela própria natureza do objeto, não pode prescindir de uma abordagem histórica.

3 Esta segunda parte foi reapresentada, sob o mesmo título, como primeiro capítulo de Desenvolvimento e Subdesenvolvimento (FURTADO, 1961). 
Sob essa perspectiva, Furtado (1954a) efetua uma revisão da economia clássica (Smith, Ricardo, Say, Stuart Mill), de Marx, da transformação neoclássica (em especial Cassel), da visão de Schumpeter e Wicksell sobre o empresário, do equilíbrio geral, e, afinal, de Hansen e da hipótese de maturidade econômica. De acordo com esta revisão, enquanto os clássicos e Marx teriam se valido largamente da noção de excedente, os neoclássicos a descartaram, ao cristalizarem a teoria da remuneração baseada na produtividade marginal. Uma vez que se admita que a estrutura da produção é determinada pela disponibilidade relativa de fatores, cada fator recebendo conforme sua "contribuição" ao processo produtivo, não há margem para se pensar em excedente econômico, muito menos em apropriação do excedente por uma ou outra classe social. Em outras rodadas de síntese ou crítica da teoria econômica ${ }^{4}$, ao revisar os modelos de crescimento a partir das contribuições de Harrod e de Domar, Furtado volta a avaliar os modelos de crescimento baseados na produtividade marginal e na substituibilidade dos fatores, externos à temática do excedente. Como foi dito, em Prefácio a Nova Economia Política a reexposição da teoria do excedente seria, de modo sintomático, acompanhada por uma revisão da teoria fisiocrática.

De modo geral, e ao longo de toda sua obra, Furtado entende que as simplificações inerentes aos modelos abstratos dificultam uma aproximação adequada à temática do desenvolvimento. Há dificuldades em incorporar aos modelos abstratos o transcurso do tempo e os processos de transformação das estruturas econômicas e sociais, assim como o reconhecimento da existência de economias com graus diversos de desenvolvimento. A admissão de que o espaço econômico é composto por economias nacionais em graus diversos de desenvolvimento - um quadro acentuado a partir da revolução industrial - exige sempre uma abordagem histórica, no interior da qual a noção de excedente e a especificação das estruturas sociais subjacentes a cada espaço nacional assumem papel destacado.

Como é natural, a revolução industrial é um ponto decisivo nas diversas abordagens do excedente de Furtado. Vale, no entanto, assinalar que, sem se referir aos impactos profundos da revolução industrial, distinguem-se em A Economia Brasileira duas lógicas econômicas distintas, a da "economia industrial" - sistema no qual os aumentos de produtividade estão liga-

4 Por exemplo, em Teoria e Política do Desenvolvimento Econômico (FURTADO, 1967). 
dos à organização da produção - e a de economias caracterizadas pelo domínio do comércio. O comércio, em si, ao romper o isolamento das unidades produtivas expande os mercados e promove especialização geográfica: o caso típico dos aumentos de produtividade causados por extensão dos mercados, especialização e divisão do trabalho, bem caracterizado por Adam Smith. Já a "economia industrial" envolve reorganização dos processos produtivos. As cidades-estado italianas (Gênova, Veneza) em seu auge comercial e financeiro são o exemplo de reorganização dos processos produtivos induzida pela intensificação do comércio escolhido por Furtado (1954a). De modo a regularizar e ampliar as exportações, os mercadores contrataram produtores antes isolados, arregimentaram pessoal, estabeleceram cadeias técnicas. Por sua vez, os adiantamentos de capital e a generalização do crédito forçaram a aceleração das vendas, para permitir a liquidação dos débitos e pagamento de compromissos diversos. Embora a expressão "economia industrial" viesse a adquirir em outros textos significado distinto, ficam caracterizados os aumentos de produtividade e de capacidade de geração de excedente proporcionados por expansão de mercados ou por reorganizações do processo produtivo, anteriores à revolução industrial. De todo modo, apenas as transformações produzidas pelos mecanismos da revolução industrial seriam capazes de proporcionar aumentos de produtividade de caráter "físico", ou aumentos de produtividade da mão de obra devidos à intensificação do uso de capital.

Além disso, um ponto essencial na obra de Furtado é o estabelecimento de fluxos monetários de pagamento de salários ou de remunerações em geral. Os fluxos monetários criam uma demanda recorrente, a qual estimulará a oferta; a concorrência, por sua vez, impede que os lucros sejam entesourados. $\bigcirc$ pagamento a fatores e a emergência de mercados denotam ainda a consolidação de sistemas de transações monetárias. A generalização das transações monetárias indica que a apropriação do excedente não se dá via coação ou por obrigações extra-mercantis; ao contrário, o excedente circulará através do intercâmbio formal e mercantil. Geração e captação de excedente de forma coercitiva seriam características de modalidades pré-mercantis de organização social. Construção de pirâmides no Egito, catedrais medievais, manutenção de séquitos senhoriais, caracterizam a distinção entre uma economia excedentária primitiva e uma economia na qual o excedente passa a ser acumulado produtivamente, induzido pela concorrência entre os capitais. 
Adiante veremos em que termos se dá a retomada da acumulação produtiva (investimentos) ou improdutiva do excedente na obra de Furtado. De todo modo, já em A Economia Brasileira, e especialmente em "O desenvolvimento econômico (ensaio de interpretação histórico-analítica)" (FURTADO, 1955) e em "Ensayo de Interpretación Histórico-Analítica del Desarrollo Económico" (FURTADO, 1956) a associação entre excedente e acumulação está presente. Na visão de Furtado, a acumulação associa-se intrinsecamente ao processo de desenvolvimento. Só pode haver acumulação - portanto, desenvolvimento - se o consumo for inferior à produção corrente; vale dizer, se houver excedente econômico. ${ }^{5}$ Nas sociedades primitivas, caracterizadas pela existência de processos produtivos pouco avançados e pela exiguidade do comércio, o excedente econômico não se destina à acumulação; já nas sociedades mercantis avançadas, especialmente nas industriais, é acumulado.

Furtado (1955) efetua longas digressões sobre o feudalismo, fenômeno associado na Europa à dispersão da população, a um certo enquistamento de unidades produtivas isoladas e à criação de novas formas de distribuição improdutiva de excedente, como a manutenção de séquitos numerosos. Apenas a conexão entre regiões e mercados, através do comércio, foi capaz de proporcionar expansão geográfica, reativação da demanda por produtos agrícolas, mobilidade de capitais em busca de melhores oportunidades... A lenta superação da ordem feudal requereu a ativação de canais de comércio e o estabelecimento de núcleos urbanos menos sujeitos à opressão do baronato. Consagrou ainda a consolidação de um novo grupo social, o dos comerciantes, capaz de concentrar recursos, abrir mercados, ampliar a especialização geográfica e a divisão do trabalho; enfim, capaz de provocar uma ruptura da ordem estabelecida e a possibilidade de expansão da acumulação.

Se apenas ao final do século XVIII a emergência de uma nova ordem produtiva na Europa parece consolidada, já nos séculos X e XI fazem-se sentir os efeitos do novo desenvolvimento proporcionado pelo comércio. Furtado apoia-se nos relatos de Pirenne e Sée sobre a dissolução do mundo feudal, a partir dos nexos e rotas comerciais estabelecidos após o cercamento de Bizâncio. Entre o século XVI e o final do XVIII dá-se afinal a emergência de uma "economia industrial" na Europa ocidental, um fenô5 Em Prefácio a Nova Economia Política, Furtado sofisticaria e tornaria mais complexa sua visão de excedente. Ver seção 3 . 
meno decisivo para o desenvolvimento econômico, por ter aberto as portas para a transformação contínua da produção e a decorrente expansão do excedente.

Note-se que a "economia industrial" antecede a revolução industrial propriamente dita. Ainda antes da revolução industrial, e imprescindível a ela, consolida-se uma nova estrutura social baseada em transações mercantis e na emergência de um polo indiscutível de captação do excedente, a classe mercantil. ${ }^{6}$ Furtado assume que a saturação das linhas de comércio no século XIV e, em reação a ela, a adoção de medidas protecionistas por diversos estados, teria acirrado a concorrência e levado a uma intervenção crescente dos comerciantes nos processos produtivos, como forma de proteção dos lucros. Estava aberta a rota de transição para uma economia revolucionada pela emergência da indústria. Com a revolução industrial do final do século XVIII, a economia industrial passa a crescer não apenas pela expansão geográfica e decorrente especialização, mas também em "profundidade".

A emergência da industrialização produz ainda uma transformação decisiva na estrutura social. Por um lado, a consolidação de uma classe importante de mercadores e, posteriormente, de capitalistas manufatureiros e fabris. Por outro, tendência ao empobrecimento dos trabalhadores manufatureiros, na passagem do artesanato à produção industrial propriamente dita. A desintegração da produção artesanal desarticulou as formas tradicionais de vida dos trabalhadores e produziu um excedente de mão de obra. Mais tarde, a organização dos trabalhadores e a demanda continuada por trabalho levariam a novo equilíbrio social, no qual o crescimento da produtividade seria acompanhado por crescimento dos salários reais. Nos países que passaram pela revolução industrial no século XIX, em algum momento a corrida entre salários reais e produtividade do trabalho passa a configurar o tamanho e os usos do excedente.

Abrindo espaço para a discussão do subdesenvolvimento, Furtado assinala em Desenvolvimento e Subdesenvolvimento que a ideia de "desenvolvimento" ressurge no debate econômico do pós-guerra como um subproduto das teorias do ciclo da primeira metade do século XX. Na medida em que a política anticíclica confunde-se com as políticas de desenvolvimento, passa-se a perguntar se a ação coordenada sobre as variáveis estratégicas do sistema econômico não poderia ser aplicada aos países subdesenvolvi6 Tema que viria a ser retomado e amplamente desenvolvido no Prefácio a Nova Economia Politica. 
dos. ${ }^{7}$ Uma resposta adequada envolveria tanto a identificação de mecanismos de crescimento quanto a explicitação das diferenças históricas entre economias desenvolvidas e subdesenvolvidas. Nas economias plenamente desenvolvidas, se não houver desocupação de fatores, o aumento de produtividade do trabalho só poderá ser obtido com novas técnicas. Já nas economias subdesenvolvidas a produtividade pode aumentar pela simples assimilação de técnicas existentes ${ }^{8}$. Como o subdesenvolvimento envolve uma utilização deficiente de fatores, em virtude da escassez de capital, basta melhorar a utilização de fatores, ou retirar a mão de obra do subemprego, para que haja crescimento da renda real.

Temos aqui uma das diversas aproximações ao mecanismo de expansão (e crescimento da produtividade) em países com excedente estrutural de mão de obra, bem identificado por Furtado já nos textos do início dos anos 1950. ${ }^{9}$ Sabe-se que nos anos 1950 e 1960, em especial em decorrência da contribuição de Lewis $(1954,1984)$ e dos debates por ela suscitados (LEWIS, 1979; TIGNOR, 2006), o modelo de crescimento com excedente de mão de obra tornou-se um ponto de referência para os estudos do desenvolvimento econômico. ${ }^{10}$ Interessa-nos aqui assinalar as particularidades da abordagem de Furtado, ou as características das diversas versões de seu modelo de crescimento com excedente de mão de obra.

Para iniciar, é importante observar que, se a possibilidade efetiva de crescimento nas economias subdesenvolvidas existe, o aumento da renda real nunca resultará para Furtado de uma ação endógena. Uma vez que o excedente disponível para o atendimento das inversões e do consumo diferenciado das camadas de altas rendas é insuficiente, sempre será necessário um impulso externo; por exemplo, expansão da demanda internacional por produtos primários, ou, posteriormente e no âmbito da industrialização por substituição de importações, incapacidade de atendimento da demanda de bens industriais pela via tradicional das importações. Em suma, havendo a possibilidade de transferir a mão de obra excedente de ocupações de baixa ou nula produtividade a outras de maior produtivida-

7 Furtado esclarece na Introdução de Desenvolvimento e Subdesenvolvimento que estas ideias, desenvolvidas em seu segundo capítulo ("O mecanismo do desenvolvimento"), haviam sido parcialmente apresentadas em Furtado (1952, 1953, 1954b).

8 A esse respeito ver também Furtado (1958).

9 Ver Furtado (1950, 1954a).

10 A respeito do modelo de desenvolvimento com excedente de mão de obra de Lewis e dos debates associados, ver Sunna (2016) e Boianovsky $(2018,2019)$. 
de, tal transferência - e a aceleração da expansão do produto - dependerá do comportamento da demanda externa ou, sob condições de restrição cambial, do esforço de substituição de importações. Crescimento induzido por aumento da demanda externa e/ou por restrições na capacidade para importar, componentes típicos da dinâmica subdesenvolvida em Furtado, são, naturalmente, caudatários dos modelos de restrição cambial impulsionados na CEPAL pelas contribuições de Prebisch. ${ }^{11}$

Além disso, a rigidez estrutural dos coeficientes técnicos na indústria leva a que os países subdesenvolvidos se industrializem com tecnologia criada nos desenvolvidos, tendo em vista a relativa escassez de mão de obra nestes prevalecente. $O$ maior problema dos países subdesenvolvidos residiria neste ponto: o desajuste entre oferta e demanda de fatores e a orientação tecnológica, ou a falta de convergência entre as escolhas técnicas e a dotação de fatores. Sob tais condições, a expansão da relação capital/trabalho na indústria restringirá a absorção da população disponível, criando subemprego e consolidando o excedente estrutural de mão de obra, o qual, por sua vez, contribui para manter a remuneração do trabalho a níveis baixos. Em outros termos, a inevitável transposição de tecnologias industriais criadas em países com dotação diversa de fatores reforça o excedente de mão de obra.

Em suma, os países subdesenvolvidos, mesmo quando se industrializam, mantêm uma estrutura ocupacional pré-capitalista e uma estrutura produtiva heterogênea, caracterizada pela existência de atividades com distintos graus de produtividade. ${ }^{12} \mathrm{O}$ excedente - drenado pela classe mercantil, por agentes de comércio exterior e industriais, por latifundistas e pela elite social - não necessariamente se dirige à acumulação interna, tanto podendo ser carreado ao exterior como dissipado em consumo suntuário. A estrutura social subdesenvolvida não se torna minimamente homogênea e as pautas de consumo não se uniformizam. Finalmente, a produtividade do capital e a taxa de poupança e de investimento não asseguram um crescimento contínuo, capaz de absorver a população sobrante e/ou de fechar a brecha que separa as economias desenvolvidas das subdesenvolvidas.

A temática do excedente econômico é um elemento essencial não apenas à abordagem do desenvolvimento econômico e do subdesenvolvi-

11 Para uma seleção das principais contribuições de Prebisch, ver Gurrieri (2011).

12 A problemática da heterogeneidade estrutural das economias latino-americanas será amplamente analisada nos anos 1970 por Anibal Pinto (1970) e Osvaldo Sunkel (1978). 
mento. Ela é parte fundamental da série de textos em que, já na década de 1950, Furtado apresenta sínteses de evolução histórica baseadas em categorias e variáveis econômicas. Formação Econômica do Brasil (1959) representa apenas o ponto culminante de uma série de trabalhos sobre a evolução da economia brasileira, de certo modo iniciada com a própria tese doutoral defendida em 1948, Economia Colonial no Brasil nos Séculos XVI e XVII (FURTADO, 2001). Um artigo publicado em 1950, "Características Gerais da Economia Brasileira", é característico desse recurso à história: a pretexto de embasar a discussão de problemas correntes da economia brasileira, Furtado apresenta neste artigo uma primeira versão das tipologias da evolução econômica brasileira desenvolvidas na década. ${ }^{13}$ Estas tipologias seriam retomadas em A Economia Brasileira, de 1954, obra na qual dois capítulos com observações teóricas sobre desenvolvimento econômico são combinados a quatro capítulos que contêm um sumário da evolução da economia brasileira em tudo antecipador de Formação Econômica do Brasil.

As sínteses da evolução histórica dão uma boa ideia da presença permanente da noção de excedente no pensamento de Furtado e oferecem novos ângulos de visualização das relações entre excedente e estrutura social. O primeiro intuito de Furtado nas sínteses históricas da economia brasileira foi caracterizar as diversas fases de sua evolução: economia colonial escravista-exportadora, economia exportadora com trabalho livre, crise do sistema primário-exportador e início da industrialização por substituição de importações, dilemas da industrialização brasileira no pós-guerra. Para um melhor enquadramento do sistema colonial brasileiro, Furtado (1959) recorre a uma distinção entre a colonização da América do Sul e a das colônias inglesas das Antilhas e da América do Norte, bem como, no interior destas duas últimas, entre colônias dominadas por pequena propriedade e as que se viram engolfadas na produção escravista de açúcar.

Nas colônias norte-americanas, dominância de pequena propriedade, consumo individual elevado e renda uniformemente distribuída levavam a que pouco excedente fluísse para o exterior. Já nas colônias antilhanas, ligadas a grupos mercantis metropolitanos, o produto por habitante livre, bastante elevado, fluía para o exterior e alimentava um padrão de vida elevadíssimo por parte dos proprietários. 
Na descrição da colonização brasileira, a temática do excedente emerge sob outro ângulo; mais precisamente, ela é parte central na descrição dos fluxos de renda na produção escravista açucareira, bem como no estabelecimento de contraste entre economia exportadora e o que Furtado denomina de "economia de subsistência". Furtado assinala que na economia exportadora açucareira havia poucos fluxos de renda monetários internos ao território. A propriedade agrícola era autossuficiente e parte expressiva da renda monetária acabava dirigida ao exterior, para pagar os financiadores da lavoura ou para manter a demanda de escravos na África. Os lucros oscilavam ao sabor dos preços externos, lucros baixos implicando retração lenta dos negócios, na medida da incapacidade de repor a mão de obra escrava. Os capitais não se mobilizariam para outros negócios, os quais, ou não existiam, ou não seriam rentáveis a ponto de permitir financiar a despesa com a escravaria.

Uma parcela da população marginal, não absorvida na lavoura de exportação, dirigia-se à "economia de subsistência". Nos textos históricos, a "economia de subsistência" caracteriza-se por pequeno ou nulo fluxo de renda monetária e inexistência de excedente. Esta peculiar visão de "economia de subsistência" - a população do sertão nordestino, que compõe a "economia de subsistência", vende gado para a região litorânea -, cumpre um papel nuclear no sistema de Furtado, uma vez que a dispersão da população pelo interior, assim como, posteriormente e com a extinção da escravidão, sua concentração nos bolsões de mão de obra em atividades urbanas de baixa produtividade, será um elemento importante do modelo de crescimento da economia brasileira a partir do final do século XIX. Simplesmente, o setor de subsistência forma a base do excedente populacional que, anos à frente, viria a cimentar o processo de industrialização com oferta ilimitada de mão de obra.

A ideia de "economia de subsistência" também lança luz sobre diversos aspectos do contraste entre excedente e subsistência, os quais acompanham a visão histórica de Furtado a respeito das economias exportadoras e do contraste entre economias mineradoras e plantation escravista. Para Furtado, economias mineradoras envolvem elevada concentração de capital e baixa absorção de mão de obra. As pesadas aplicações de capital no núcleo minerador exercem pouco impacto sobre o restante do território e da população, sendo o excedente das minas em grande parcela transferido aos operadores metropolitanos. $\bigcirc$ excedente dos enclaves mineradores 
tem pouco efeito de arrasto econômico sobre o restante do território.

A mineração de ouro no Brasil no século XVIII teria representado um caso especial, distinto do enclave minerador típico. Para começar, as minas podiam ser exploradas com dotações diversas de capital, e atraíram trabalhadores da metrópole. Havia, portanto, uma combinação de trabalho livre e escravo. Além disso, nas regiões mineradoras desenvolveram-se importantes núcleos urbanos. $\mathrm{O}$ abastecimento da população urbana e do contingente de trabalhadores voltados exclusivamente ao trabalho de mineração desenvolveu uma rede de fornecedores de alimentos. Por outro lado, a distância da região mineradora ao litoral e às regiões produtoras de alimentos requereu um volumoso sistema de transporte por animais de carga. Por todas essas razões, o fluxo de recursos entre as minas e as outras regiões e atividades econômicas teria permitido algum grau de diversificação econômica, o que reduziu a drenagem de excedente por parte do estado e da metrópole e produziu alguma especialização e estratificação social no território colonial.

Para Furtado, a própria plantation exportadora brasileira, apesar da escassa monetização das atividades internas ao território colonial, teria exercido impacto sobre o restante do território maior que o da plantation antilhana característica. A magnitude do impacto dependeria da mão de obra utilizada (escrava ou livre), do grau de monetização e de mercantilização da economia adjacente à plantation, do tamanho dos núcleos urbanos, da relação com a economia metropolitana. Na economia açucareira antilhana, a dominância absoluta da população escrava indicava transferência elevada de excedente para as metrópoles. Nas plantations brasileiras de açúcar e de café, o maior contingente de população livre, a existência de alguma urbanização, as comunicações estabelecidas com economias regionais, podiam implicar efeitos realimentadores, alguma retenção de excedente no território e até mesmo - é o caso do café - aplicações significativas de capital em atividades adjacentes, como transportes e comércio.

De todo modo, no Brasil, ao término da escravidão, a população já livre no território ou liberada pelo processo emancipatório progressivo não afluiu imediatamente aos cultivos de exportação de alta rentabilidade, como o café. A constituição de um mercado de trabalho livre requereu a imigração de trabalhadores europeus. Em particular em Formação Econômica do Brasil, Furtado (1959) explora as razões pelas quais uma população livre, dispersa pelo território ou mesmo sediada em núcleos urbanos, não veio a 
se constituir imediatamente em mão de obra disponível para as atividades que demandassem trabalho, inclusive nos ramos mais dinâmicos da agricultura de exportação, como o café. ${ }^{14}$ De todo modo, passado o momento inicial de constituição de um mercado de trabalho livre com população imigrada, paulatinamente a população excedente veio a pressionar os mercados de trabalho urbano e rural. Sob o ponto de vista da formação do excedente e da constituição da estrutura social, o fundamental é que, uma vez estabelecida a intercomunicação entre a população sobrante e os mercados de trabalho, a economia urbana e industrial subsequente conviveria com um excedente populacional e com os baixos rendimentos do trabalho moldados no período primário-exportador.

É importante assinalar outros fatores incidentes sobre a formação de preços e a distribuição de renda que receberam atenção em Furtado (1954a, 1955). Um deles é a dinâmica cambial, chave da transição para a industrialização e que atuara como elemento concentrador ainda no período primário-exportador. Furtado refere-se no caso aos acordos de compra de excedentes de café pelo governo, uma política empreendida a partir de 1906 visando a administração da oferta externa do produto e a atenuação das quedas de preços. Tais acordos viriam a se somar à política de "socialização das perdas" ensejada pela desvalorização cambial, a qual representou uma política de transferência de renda de todos os consumidores de produtos importados aos exportadores de café. Em diversos outros momentos da história econômica brasileira subsequente, desvalorização cambial ou seu contrário (sustentação da taxa de câmbio apesar da inflação interna), mecanismos de racionamento governamental do acesso a câmbio, taxas cambiais escalonadas conforme os bens a serem importados, representaram mecanismos com incidência sobre a formação de preços e as transferências de renda associadas. O impacto desses variados fatores sobre os preços relativos, a concentração de renda e a formação de excedente, viria a receber um tratamento mais integrado em Subdesenvolvimento e Estagnação na América Latina (1966), trabalho que destaca ainda que as firmas industriais que se lançaram à substituição de importações no pós-

14 Versiani (2009) efetua um levantamento bastante completo do "problema da mão de obra" em Formação Econômica do Brasil. Em síntese, a estrutura de posse da terra, a forma de subordinação dos trabalhadores livres aos proprietários rurais, a possibilidade de obtenção de subsistência em atividades rurais de baixa produtividade em regime de colonato ou de parceria, assim como a existência de uma ampla marginalidade urbana, obstaculizaram a formação imediata de um mercado de trabalho assalariado. 
1930 operaram sempre em ambiente monopolista ou oligopolista, com as devidas implicações na formação de preços e lucros.

Outro elemento decisivo na conformação da estrutura distributiva no pós-guerra foi a inflação. Tanto em A Economia Brasileira quanto em Formação Econômica do Brasil, Furtado se detém nos efeitos da política cambial e dos mecanismos de crédito sobre a recorrente inflação brasileira. Como se sabe, Furtado participara na CEPAL de diversas discussões sobre a inflação latino-americana, havendo se tornado um dos formuladores da hipótese estruturalista da inflação. ${ }^{15}$ Nos textos de caráter histórico, bem como nos debates sobre os dilemas da industrialização brasileira no pós-guerra, a inflação comparece como um dos mecanismos de transferência de renda que moldam a estrutura de rendimentos, sempre em detrimento da população pobre. A inflação e a política cambial brasileiras, portanto, são elementos que conformam a estrutura social e a estratificação de rendimentos, superpondo-se a outros fatores, como oferta ilimitada de mão de obra e políticas fiscais com viés concentrador. Ao proporcionarem um impulso adicional a uma concentração de renda já histórica, exercerão impacto sobre as possibilidades de difundir o consumo dos bens industriais. Diversificação do consumo e incorporação de produtos à cesta de consumo dos diversos segmentos da população seria o tema retomado, com novas abordagens, na obra de Furtado da segunda metade dos anos 1960 e anos 1970.

\section{Em busca de um novo quadro conceitual para o estudo do desenvolvimento: excedente, estratificação social e poder}

Em suas primeiras elaborações teóricas sobre os problemas do desenvolvimento econômico, Furtado já chamava a atenção para as implicações do sistema de dominação social sobre a possibilidade de canalização do excedente para a acumulação, como relembra em um dos volumes de sua autobiografia (FURTADO, 1985). Analisando o processo de industrialização latino-americano ocorrido ao longo dos anos 1950 e 1960, Furtado observaria a necessidade de um tratamento mais abrangente do processo 
de acumulação. Impunha-se uma reavaliação do processo de desenvolvimento, que se inicia, nos textos dos anos 1970, com o excedente.

Como vimos, em textos anteriores Furtado já enfatizava as conexões entre excedente e acumulação no estudo do desenvolvimento, e chamava a atenção para as relações existentes entre a destinação final do excedente e o sistema produtivo. Em Prefácio a Nova Economia Política, Furtado colocaria em destaque as diferentes formas que pode assumir a acumulação num sistema econômico. A acumulação improdutiva apresentava-se como uma das formas de utilização do excedente social, relacionada, por exemplo, a objetivos de consolidação de estruturas de poder (como a construção de pirâmides e a manutenção de cortes) e de estruturas de estratificação social (ligadas à diferenciação de formas de consumo). A acumulação que corresponde ao aumento da capacidade produtiva (investimentos) seria, assim, apenas uma das possibilidades de acumulação. Além da forma particular "acumulação-investimento", cabia, portanto, investigar as demais formas de utilização do excedente social. Para tal, a percepção de outras dimensões do processo social, além da econômica, seria necessária. Furtado (1976a, p. 11) preconiza, então, a própria reconstrução do quadro conceitual dos economistas, com base em uma "visão global de estruturas sociais historicamente identificadas".

Sintomaticamente, no Prefácio Furtado inicia sua revisão da ciência econômica chamando a atenção para as ligações entre a forma de apropriação do excedente e a estrutura de classes de uma sociedade. Na medida em que a exclusão das estruturas sociais da análise econômica corresponderia à aceitação da imutabilidade das estruturas existentes, o estudo do processo de desenvolvimento - que implica transformações estruturais - requeria a retomada do conceito de excedente, que viabilizaria a realização de uma análise global do processo de acumulação e de suas relações com as estruturas sociais.

O conceito de excedente permitiria, assim, abarcar todo o horizonte de opções sobre o futuro aberto a uma comunidade cuja produtividade do trabalho se encontrasse acima do nível de subsistência, ou seja, que dispusesse de meios acima do necessário a sua reprodução. Como mencionamos anteriormente, Baran e Furtado foram pioneiros na utilização do conceito de excedente para a explicação do subdesenvolvimento. Baran também salienta em sua análise a questão das opções abertas à sociedade pela existência de um excedente, evidenciando as relações entre exceden- 
te e estruturas de classe nos países subdesenvolvidos. ${ }^{16}$ No entanto, conforme a análise de Victor Lippit (1985), a ênfase dada por Baran às forças externas incidentes sobre os países subdesenvolvidos inibiria a aplicação do conceito de excedente ao estudo do desenvolvimento. Baran teria, assim, negado a relevância das estruturas internas nos países subdesenvolvidos: a criação de elites dependentes inviabilizaria a passagem de formas pré-capitalistas para formas capitalistas de produção, impondo-se a revolução socialista para a realização do desenvolvimento (LIPPIT, 1985). Sabidamente, essa não é a perspectiva de Furtado, apesar de sua atenção aos condicionantes externos do subdesenvolvimento. De seu ponto de vista, as possibilidades de evolução abertas a uma sociedade em decorrência da existência de excedente são delimitadas pela forma de apropriação desse excedente e pelos usos a ele dados, que podem incluir tanto o aumento da capacidade produtiva quanto a promoção da melhoria do bem-estar social ou o estímulo ao desperdício de minorias privilegiadas (FURTADO, 1964, 2008). O estilo de desenvolvimento de um país seria, então, conformado pelas opções feitas por grupos capazes de se apropriar desse excedente e de exercer poder sobre os demais. Se é a presença de níveis de consumo desiguais em uma coletividade que comprova a existência de um excedente, a teoria do excedente apresenta-se como "a face econômica da teoria da estratificação social" (FURTADO, 1976a, p. 18). E, na medida em que a estratificação social é sempre acompanhada por estruturas de poder, o novo quadro conceitual proposto por Furtado (1976a, 1976c) abarcaria as teorias do excedente econômico, da acumulação, da estratificação social e do poder.

A identificação do nível de vida das massas - o custo de reprodução de um trabalhador manual, variável conforme a história de cada sociedade - seria o ponto de partida para medir a estratificação social. Os preços relativos praticados nos mercados seriam um instrumento para a medição da apropriação do excedente. Assim, o cálculo do custo de reprodução da população (com base em uma cesta de bens a que tem acesso o trabalhador manual) - e, portanto, do excedente - só poderia ser realizado em cada país, conforme seu próprio sistema de formação de preços. Dessa forma,

16 Ademais, seguindo Szmrecsányi (2001), vale lembrar que, guardadas as diferenças metodológicas entre os dois autores, há semelhança entre suas interpretações sobre as origens históricas das estruturas subdesenvolvidas a partir da expansão das economias industrializadas para regiões com estruturas pré-capitalistas. 
considerando que o custo de reprodução da população varia em função de cada sistema interno de dominação, Furtado critica a ideia presente na doutrina do "intercâmbio desigual" (EMMANUEL, 1969), segundo a qual seria possível estabelecer uma cesta de bens que servisse de medida para o custo de reprodução da população em escala internacional. O intercâmbio internacional, na medida em que aumenta a produtividade, poderia promover tanto a elevação do excedente quanto do nível de vida das massas (em decorrência de pressões para elevação do custo de reprodução da população). O nível do excedente seria então determinado, segundo Furtado, pela produtividade social do trabalho e pelo perfil de repartição da renda em cada sociedade. Ao colocar em evidência a diversidade de formações socioeconômicas capitalistas existentes, o estudo do excedente (de seu nível, de sua destinação final e das forças sociais que dele se apropriam) teria especial importância para o estudo das economias subdesenvolvidas.

Além disso, o conceito de excedente seria aplicável a todas as formações sociais, diferentemente do conceito de mais-valia, de aplicação restrita a economias de mercado (FURTADO, 2008, 1976a). A postura crítica de Furtado em relação à pertinência da abordagem de Marx para o estudo dos problemas do desenvolvimento é, assim, reafirmada em sua defesa da utilização do conceito de excedente que, apesar das dificuldades técnicas envolvidas em sua medição, evitaria dificuldades como a diferenciação entre trabalho produtivo e não-produtivo, além de ser amplo o suficiente para a abordagem do problema da acumulação também em formações sociais pré e pós-capitalistas (FURTADO, 1977). O autor exprime, ademais, dúvidas em relação à aplicabilidade do "conceito de mais-valia tal qual o definiu Marx" no "capitalismo 'Organizado' de hoje, onde os trabalhadores negociam coletivamente com os patrões e estes 'administram' os preços finais do produto" (FURTADO, 1977).

Em estudos anteriores, Furtado $(1958,1961,1967)$ havia mostrado as circunstâncias históricas que levaram à adoção, em economias subdesenvolvidas, de tecnologias intensivas em capital, responsáveis pela perpetuação da heterogeneidade tecnológica e do subemprego (atividades não beneficiadas por aumentos de produtividade física). A especificidade do subdesenvolvimento como formação social distinta, que tende a se reproduzir, e não como etapa que precede o desenvolvimento, como já explicitado em seus escritos da década de 1950 (FURTADO, 1961) é, no Prefácio, explicada de um ponto de vista comparativo entre "o comportamento no 
tempo do custo de reprodução da população e o da acumulação ao nível das atividades produtivas" (FURTADO, 1976a, p. 25). O subdesenvolvimento apresenta-se, assim, como um fenômeno social maior do que a acumulação ou o grau de industrialização de um país: o subdesenvolvimento está ligado às estruturas sociais. O Brasil seria "um caso típico de país subdesenvolvido industrializado", na medida em que avançou no processo de industrialização sem promover modificações em suas estruturas sociais (FURTADO, 1976b). De modo geral, diversamente do que ocorre nas economias desenvolvidas, nas economias subdesenvolvidas o custo de reprodução da população tenderia a crescer menos do que a produtividade social, sendo observado aumento da participação do excedente no produto (que, no entanto, não resultaria em maior esforço de acumulação no sistema produtivo).

A análise de Furtado $(1961,1974)$ mostra que a elevação de produtividade decorrente da especialização internacional e da expansão do intercâmbio criou condições, em certas regiões, para a formação de excedente e para a apropriação por grupos específicos de partes do produto social. $\mathrm{O}$ acesso a bens de consumo que incorporavam o progresso técnico em desenvolvimento nos países que se industrializavam foi, assim, viabilizado em regiões que não experimentavam um processo concomitante de acumulação ao nível das forças produtivas. Na desconexão entre os usos dados a esse excedente adicional e o processo de formação de capital, Furtado identificaria a origem das formações sociais subdesenvolvidas. Essa canalização do excedente para o financiamento da difusão de novos padrões de consumo (para grupos minoritários da população) seria o reflexo de um fenômeno de dependência cultural com implicações decisivas para a industrialização periférica.

Como Furtado enfatiza, especialmente a partir dos escritos reunidos em Subdesenvolvimento e Estagnação na América Latina (1966) e, sobretudo, em suas análises críticas do período do "milagre" econômico brasileiro (FURTADO, 1972, 1974), a industrialização periférica, que avança sob controle de empresas multinacionais, ao mesmo tempo que viabilizava a reprodução de padrões de consumo dos países centrais por minorias dos países subdesenvolvidos, contribuía à consolidação das estruturas políticas existentes, bem como das estruturas de distribuição da renda. Para o processo de desenvolvimento, seria necessário, então, um esforço de reconstrução das estruturas sociais. Daí a importância da retomada 
do estudo do excedente para o aprofundamento da compreensão "das estruturas internas de dominação e das relações externas de dependência" (FURTADO, 1976a, p. 27).

Crucial, portanto, para o estudo do desenvolvimento das forças produtivas, seria conhecer o sistema de dominação social e a estrutura de poder vigentes, na medida em que o poder reflete-se materialmente na capacidade de criação e/ou apropriação do excedente. Analisar as diferentes formas de poder observadas numa sociedade, bem como os "conflitos e interações que estão na base da formação do excedente e que condicionam sua utilização final" (FURTADO, 1976a, p. 28) seria fundamental para a percepção das opções abertas a uma sociedade. O poder teria, assinala Furtado, uma dimensão política e outra econômica, ligadas ao uso da coação e à formação-aplicação do excedente. Assimilando as decisões econômicas a automatismos, os economistas ocultariam o elemento de poder presente nestas. Vale aqui mencionar, em relação à questão do poder, a aproximação entre os pensamentos de Furtado e do economista francês François Perroux (com quem tivera contato durante seus estudos doutorais em Paris). Perroux, em suas obras, denuncia a distinção entre fatores econômicos e sociais que permitiria à teoria econômica ortodoxa ignorar o fenômeno do poder: a Economia restringir-se-ia, assim, a ser uma ciência dos "meios", pertencendo os "fins" ao domínio da moral e da política. Tal postura colocaria o economista em posição de aceitação da ordem social existente e da hierarquia de poderes que a constitui (PERROUX, 1973). Furtado reforça, por sua vez, a partir do Prefácio, a necessidade de abandono de uma visão economicista da sociedade (em que se projeta luz apenas sobre alguns aspectos da realidade) em prol de uma visão global das estruturas sociais, necessária para estudo das formas de apropriação do excedente, de fundamental importância para a compreensão dos problemas do subdesenvolvimento.

As implicações do progresso tecnológico no processo de desenvolvimento das economias periféricas, tema caro a Furtado, estão presentes desde seus primeiros escritos, como salientamos na seção anterior. ${ }^{17}$ Tais questões são repostas e desenvolvidas ao longo de sua obra, com especial ênfase ao exercício de poder presente no controle da tecnologia. Tendo sido orientado no sentido de compensar a relativa rigidez da oferta de mão 
de obra que se seguiu à fase inicial do processo de industrialização nas economias centrais, o progresso técnico (e o favorecimento de inovações técnicas poupadoras de mão de obra) teria permitido a superação de tensões derivadas de pressões por elevação da participação dos trabalhadores na apropriação do produto social, constituindo-se em instrumento de poder para a conservação de privilégios na sociedade capitalista. A evolução do sistema produtivo estaria, ademais, condicionada por uma orientação do progresso tecnológico no sentido da diversificação do consumo, que faria com que, nas sociedades desenvolvidas, produtos inicialmente reservados às minorias fossem difundidos, posteriormente, a setores mais amplos. Mantendo-se em expansão a economia, as expectativas dos diferentes agentes viriam a ser satisfeitas. Progresso tecnológico e sistema de dominação estariam, assim, conectados no sentido da manutenção da estabilidade da estrutura social e da apropriação do excedente.

Furtado (1976a) salienta que a margem de participação dos trabalhadores manuais na apropriação do produto social - relevante para a medição da estratificação social - é determinada por condicionantes históricos e culturais. Se o excedente econômico é fruto da divisão social do trabalho, sua apropriação, no entanto, depende do quadro institucional vigente. Nos países que desfrutavam de níveis relativamente elevados de vida no momento em que passa a predominar o modo capitalista de produção ${ }^{18}$, a taxa de salários teria tendido a se manter elevada em relação à produtividade social (FURTADO, 1976a, p. 49). Já nos países periféricos, as modificações na estrutura social decorrentes do processo de industrialização não teriam sido acompanhadas por correspondente avanço nas instituições políticas. Em economias caracterizadas por dualismo estrutural "a apropriação do excedente pelos grupos dirigentes não [encontraria] resistência nos trabalhadores" (FURTADO, 1964, p. 30). Derivado da absorção de tecnologias tomadas de empréstimo a realidades socioeconômicas distintas, amplo su-

18 Note-se que Furtado (1976a), reelaborando ideias já explicitadas em seus textos da década de 1950, estabelece uma diferenciação entre capitalismo e modo capitalista de produção: se o capitalismo sempre existiu onde existiu a forma mercantil de apropriação do excedente, o modo capitalista de produção seria próprio do século XVIII, quando passa a predominar um modo de apropriação do excedente por meio da aplicação do critério mercantil ao nível da organização da produção. Nesse sentido, ao mesmo tempo que salienta a contribuição de Max Weber "para a compreensão do fenômeno do capitalismo", Furtado afirma sua discordância em relação à posição desse autor no que se refere à incompatibilidade entre capitalismo e formas servis de trabalho. Daí seu recurso à expressão "modo capitalista de produção" (usada por Marx) para assinalar que a "predominância do trabalho livre constitui marco decisivo na evolução do capitalismo" (Furtado, 1976a, p. 37, n. 27). 
bemprego estrutural permaneceria durante o processo de industrialização por substituição de importações. Persistindo o dualismo e uma estrutura social excludente - caracterizada por distribuição desigual da renda e heterogeneidade dos padrões de consumo entre os diferentes grupos da população -, estariam comprometidas a própria continuidade do processo de industrialização e as possibilidades de superação do subdesenvolvimento (FURTADO, 1966; BIANCONI, 2016).

Especialmente em suas obras dos anos 1970, Furtado (1972, 1974, 1976a) destaca as implicações sobre o desenvolvimento periférico do processo de modernização viabilizado por incrementos de excedente propiciados pela expansão do intercâmbio internacional. Em certas regiões, o excedente adicional, ao ser em parte apropriado por grupos locais - muitas vezes ligados a estruturas tradicionais de organização da produção e a uma via autoritária de extração do excedente -, teria viabilizado a incorporação de novos padrões de consumo por minorias privilegiadas, sendo o progresso técnico prioritariamente assimilado por meio de novos produtos incorporados à cesta de consumo. Em outras regiões, no entanto, intensificava-se o processo de acumulação nas forças produtivas, com assimilação de progresso técnico sob forma de processos produtivos mais eficazes. O sistema de divisão internacional do trabalho teria, portanto, permitido a integração de estruturas socioeconômicas díspares. Como salienta Furtado, a partir do contato entre diferentes culturas, "uma cultura orientada para a expansão e a inovação e outras orientadas para a tradição, surgiu um efeito de dominação da primeira sobre as segundas, que tenderam a aspirar a reproduzir os padrões de consumo da primeira" (FURTADO, 1976a, p. 54).

As economias periféricas teriam experimentado um processo de dominação cultural, materializado em incorporação mais intensa de progresso técnico nos padrões de consumo do que nas formas de produção. Furtado observa, assim, um processo de "imposição de padrões de cultura" (FURTADO, 1976a, p. 55) em decorrência do processo de formação do sistema de divisão internacional do trabalho, que condicionaria o processo de acumulação nas economias periféricas em que a industrialização realizou-se sob a forma de substituição de importações. Ao avançar esse processo de industrialização nas economias tecnologicamente atrasadas, dificuldades adicionais seriam impostas pela emergência de novas formas de difusão do progresso tecnológico através da implantação de atividades industriais de propriedade estrangeira nos países periféricos (ver também FURTADO, 1974). 
Antes de o fenômeno da transnacionalização ocupar lugar de destaque em suas reflexões, Furtado (1964) já apontava para um processo de evolução do dualismo característico das economias periféricas: da forma tradicional de dualismo entre os setores de subsistência e mercantil, o dualismo teria evoluído para um novo tipo durante o processo de industrialização, agora entre setores altamente capitalizados e aqueles empregando técnicas tradicionais ou com baixo nível de investimento em capital. Na década de 1970, avançando em sua interpretação sobre a evolução da economia capitalista, Furtado $(1974,1975)$ salientaria o aprofundamento da divisão do trabalho promovida pelas atividades transnacionais, ao submeterem recursos produtivos internacionais a uma mesma unidade de comando. Controlando e planejando a produção em um espaço plurinacional, as atividades transnacionais contribuiriam a reduzir pressões para a elevação do custo de reprodução dos trabalhadores nos países em que estes haviam alcançado maior grau de organização. Nos países marcados por atraso no processo de acumulação, à medida que se intensificava a industrialização e as necessidades de capital aumentavam, as atividades de produção tenderam a ser controladas por grandes empresas de ação transnacional. Da orientação do processo de industrialização na periferia por grandes empresas estrangeiras decorria um aprofundamento do transplante de formas de vida que correspondem a países de nível de acumulação mais elevado. Aprofundava-se, assim, a dependência cultural, implicando drenagem suplementar do excedente social para a adoção de novos padrões de consumo, permanentemente renovados. De modo similar evoluiria o pensamento de Raúl Prebisch em seus últimos trabalhos (PREBISCH, 1981), em que o autor denuncia o que chama de "sociedade privilegiada de consumo" e defende a necessidade de um "uso social do excedente". Para tanto, considerando que no tratamento dos problemas do desenvolvimento econômico não é possível desconectar os fatores econômicos das estruturas sociais, também Prebisch destacaria a necessidade de se alargar o campo de visão para além da teoria econômica.

Especialmente em Criatividade e Dependência na Civilização Industrial (1978) e em Pequena Introdução ao Desenvolvimento (1980), desenvolvendo o quadro conceitual apresentado em Prefácio a Nova Economia Política (1976), Furtado aprofundaria seu enfoque interdisciplinar dos problemas do desenvolvimento. ${ }^{19}$ Enfatizando o problema da progressiva subordinação da 19 A propósito da obra de Furtado dos anos 1970, ver também o artigo de Cunha e Britto (2018). 
criatividade humana ao processo de acumulação, o autor salientaria que os meios tenderam a ser vistos como fins no processo de expansão da civilização industrial. A inventividade técnica encontrar-se-ia, assim, subordinada "aos interesses de reprodução de uma sociedade fortemente inigualitária e de elevado potencial de acumulação" (FURTADO, 1980, p. 18). A esse respeito, vale lembrar que os problemas ecológicos derivados da expansão da civilização industrial e, notadamente, o desperdício de recursos decorrente do estímulo à renovação permanente dos padrões de consumo inerente à evolução dessa civilização, são enfatizados em sua obra produzida a partir dos anos 1970 (FURTADO, 1974, 1978). No caso de sociedades que adotaram os valores materiais da civilização industrial pela via de "acesso indireto" proporcionada por excedentes adicionais advindos da expansão do comércio internacional, a ideia de desenvolvimento teria surgido essencialmente ligada ao transplante da civilização industrial, de um estilo material de vida, restringindo-se a compreensão do desenvolvimento à elevação dos níveis de vida por meio do aumento e diversificação do consumo. Nesse contexto, o processo de industrialização dependente assumiria um caráter adaptativo a uma demanda preexistente, que seria responsável pela perpetuação da heterogeneidade social e produtiva, ao não promover a absorção da mão de obra excedente e requerer permanente renovação dos vínculos de dependência a economias mais avançadas no processo de acumulação.

\section{Observações finais}

A ideia de excedente integra o arcabouço teórico de Celso Furtado desde os anos 1950, quando o autor coloca em destaque as insuficiências da teoria econômica para o tratamento dos problemas do desenvolvimento das economias periféricas (FURTADO, 1954a, 1958, 1961). Ao apreender o desenvolvimento como um processo de transformações sociais, Furtado mostra que a possibilidade de mudança é dada pela existência de recursos que ultrapassam o estritamente necessário à sobrevivência de uma comunidade. A possibilidade de realizar efetivas opções sobre o futuro abre-se, assim, a uma coletividade em que se verifica a existência de excedente social.

Da dimensão e do modo de utilização do excedente de recursos criado pela divisão social do trabalho dependem as transformações a serem empreendidas em um sistema econômico. Furtado chama a atenção para 
a importância da compreensão das confrontações entre grupos sociais no que se refere ao custo de reprodução da população e à destinação final do excedente. Dessa forma, se a existência de um excedente abre um horizonte de opções à sociedade e capacita-a para a autotransformação, os conflitos em torno da apropriação do excedente, enquanto fatores decisivos para a determinação da orientação geral do desenvolvimento econômico, devem ser estudados. Furtado não ignora as dificuldades técnicas envolvidas na medição do excedente - baseada em comparação entre o custo de reprodução do conjunto da população e a produtividade social do trabalho -, chamando a atenção, por exemplo, para o fato de que parte dos recursos apropriados pelo Estado não integra o excedente, mas compõe o custo de reprodução dos trabalhadores. Apesar das dificuldades envolvidas no cálculo do excedente, Furtado retoma esse conceito e transforma-o em elemento essencial de sua busca de instrumentos para explicar o processo de mudança social.

Para Furtado, importava conhecer os mecanismos de utilização da renda social numa comunidade em que os níveis de produtividade do trabalho estavam acima de seu nível de subsistência, em que se abria a possibilidade de acumulação, ou seja, de transferência da utilização de recursos para o futuro. Seu objeto de estudo sendo o desenvolvimento, Furtado procura compreender as relações entre a utilização do excedente e o sistema produtivo. As opções feitas pelos agentes que se apropriam do excedente ganham, assim, destaque em sua abordagem, na medida em que a acumulação nas forças produtivas é apenas uma das possibilidades de utilização do excedente (o excedente também pode ser absorvido, em sua totalidade, pelo consumo e por investimentos improdutivos - ou sua reposição). Nesse sentido, a discussão sobre a adoção, por grupos privilegiados de uma sociedade, de padrões de consumo importados, e a dependência cultural presente na origem desse processo, marcam a obra de Furtado.

Como procuramos mostrar neste artigo, a temática do excedente é central na abordagem de Furtado dos processos de desenvolvimento e subdesenvolvimento. Em suas obras de natureza histórica, bem como em suas reavaliações da ciência econômica e das contribuições desta à compreensão dos problemas do desenvolvimento, revela-se a importância do conceito de excedente: o subdesenvolvimento configura-se a partir de formas específicas de apropriação e utilização de excedentes gerados pela expansão do intercâmbio internacional e decorrentes aumentos de produtivida- 
de na periferia do sistema capitalista. As estruturas sociais subjacentes às formas específicas de geração, apropriação e utilização do excedente serão parte essencial de sua explicação do subdesenvolvimento. Com a observação dos processos de industrialização periféricos e das transformações na economia internacional, evoluiu também a abordagem de Furtado sobre as relações entre excedente e estruturas sociais no processo de desenvolvimento. Especialmente em sua obra produzida a partir dos anos 1970, o desenvolvimento econômico é relacionado à criatividade, à criação de valores culturais, que ocorrem conforme são liberadas as energias potenciais existentes na vida social. E é a existência de excedente que libera uma comunidade da mera reprodução social, configurando, portanto, "um desafio à inventividade" (FURTADO, 2002).

A desigualdade entre padrões de consumo em uma sociedade mostra a estratificação social nela presente e permite compreender as formas de dominação responsáveis pela desigualdade na repartição do produto social. A retomada do conceito de excedente e do estudo de suas relações com as estruturas sociais abria, assim, a possibilidade de uma compreensão mais abrangente dos problemas do desenvolvimento, num momento em que a consolidação de novas formas de exercício de poder em nível internacional parecia tornar mais difícil a superação do subdesenvolvimento.

\section{Referências}

BARAN, P.A. Economic Progress and Economic Surplus. Science \& Society, New York, v. 17, n. 4, p. 283-289, 1953.

BARAN, P.A. The Political Economy of Growth. New York: Monthly Review, 1957.

BARAN, P.A.; SWEEZY, P. Monopoly capital: an essay of the American economic and social order. New York: Modern Reader, 1966.

BIANCONI, R. Estagnação latino-americana e estratégia brasileira de desenvolvimento: análises do início do exílio de Celso Furtado. História Econômica \& História de Empresas, São Paulo, v. 19, n. 1, p. 155-188, 2016.

BIANCONI, R. Subdesenvolvimento, tecnologia e padrões de consumo: discussões a partir da obra de Celso Furtado. Cadernos do Desenvolvimento, Rio de Janeiro, v. 13, n. 23, p. 103$128,2018$.

BOIANOVSKY, M. A View from the Tropics: Celso Furtado and the Theory of Economic Development in the 1950s. History of Political Economy, Durham, v. 42, n. 2, p. 221-266, 2010. 
BOIANOVSKY, M. Celso Furtado and the Structuralist-Monetarist Debate on Economic Stabilization in Latin America. History of Political Economy, Durham, v. 44, n. 2, p. 277-330, 2012.

BOIANOVSKY, M. When the history of ideas meets theory: Arthur Lewis and the classical economists on development. History of Political Economy, Durham, v. 50, p. 172-190, 2018. Suplemento.

BOIANOVSKY, M. Arthur Lewis and the classical foundations of development economics. Research in the History of Economic Thought and Methodology, Bingley, v. 37A, p. 103-143, 2019.

COUTINHO, M. A Economia Brasileira (1954), de Celso Furtado. História e Economia, São Paulo/Lisboa, v. 18, n. 1, p. 39-61, 2017.

CUNHA, A. M.; BRITTO, G. When development meets culture: the contribution of Celso Furtado in the 1970s. Cambridge Journal of Economics, v. 42, n. 1, p. 177-198, 2018.

EMMANUEL, A. L'échange inégal. Paris: Maspero, 1969.

FURTADO, C. Características Gerais da Economia Brasileira. Revista Brasileira de Economia, Rio de Janeiro, v. 4, n. 1, p. 7-37, 1950.

FURTADO, C. Formação de capital e desenvolvimento econômico. Revista Brasileira de Economia, Rio de Janeiro, v. 6, n. 3, p. 7-45, 1952.

FURTADO, C. La formación de capital y el desarrollo económico. El Trimestre Económico, México, v. 20, n. 77(1), p. 88-121, 1953.

FURTADO, C. A Economia Brasileira (Contribuição à análise de seu desenvolvimento). Rio de Janeiro: A Noite, 1954a.

FURTADO, C. Capital Formation and Economic Development. International Economic Papers, Londres, v. 4, p. 124-144, 1954 b.

FURTADO, C. O desenvolvimento econômico (ensaio de interpretação histórico-analítica). Econômica Brasileira, Rio de Janeiro, v. 1, n. 1, p. 3-23, 1955.

FURTADO, C. Ensayo de Interpretación Histórico-Analítica del Desarrollo Económico. El Trimestre Económico, México, v. 23, n. 90(2), p. 151-176, 1956.

FURTADO, C. Comentários sobre estudos do Professor Rosenstein-Rodan. Econômica Brasileira, Rio de Janeiro, v. 4, n. 3-4, p. 119-125, 1958.

FURTADO, C. Formação Econômica do Brasil. Rio de Janeiro: Fundo de Cultura, 1959.

FURTADO, C. Desenvolvimento e Subdesenvolvimento. Rio de Janeiro: Fundo de Cultura, 1961.

FURTADO, C. Dialética do Desenvolvimento. Rio de Janeiro: Fundo de Cultura, 1964.

FURTADO, C. Subdesenvolvimento e Estagnação na América Latina. Rio de Janeiro: Civilização Brasileira, 1966.

FURTADO, C. Teoria e politica do desenvolvimento econômico. São Paulo: Companhia Editora Nacional, 1967.

FURTADO, C. Análise do "Modelo" Brasileiro. Rio de Janeiro: Paz e Terra, 1972.

FURTADO, C. O Mito do Desenvolvimento Econômico. Rio de Janeiro: Paz e Terra, 1974.

FURTADO, C. O capitalismo pós-nacional: uma interpretação da "crise" econômica atual. 
Cadernos de Opinião, Rio de Janeiro, v. 1, p. 5-25, 1975.

FURTADO, C. Prefácio a Nova Economia Política. Rio de Janeiro: Paz e Terra, 1976a.

FURTADO, C. Vim provocar debates. [Entrevista cedida a] Emília Silveira. Jornal do Brasil, Rio de Janeiro, Caderno B, p. 1, 16 set. 1976 b.

FURTADO, C. Por uma nova teoria econômica [Entrevista]. Opinião, Rio de Janeiro, p. 7-9, 24 set. 1976 c.

FURTADO, C. Bem-aventurados os que não precisam de uma nova economia política. Opinião, Rio de Janeiro, p. 9, 14 jan. 1977.

FURTADO, C. Criatividade e dependência na civilização industrial. Rio de Janeiro: Paz e Terra, 1978.

FURTADO, C. Pequena introdução ao desenvolvimento. São Paulo: Companhia Editora Nacional, 1980.

FURTADO, C. A fantasia organizada. Rio de Janeiro: Paz e Terra, 1985.

FURTADO, C. Economia Colonial no Brasil nos Séculos XVI e XVII. São Paulo: Hucitec/ABPHE, 2001.

FURTADO, C. Em busca de novo modelo. São Paulo: Paz e Terra, 2002.

FURTADO, C. Economia do desenvolvimento: curso ministrado na PUC-SP em 1975. Rio de Janeiro: Contraponto/Centro Internacional Celso Furtado, 2008.

FURTADO, C. Obra Autobiográfica. São Paulo: Companhia das Letras, 2014.

GURRIERI, A. (org.). O Manifesto Latino-Americano e outros ensaios. Rio de Janeiro: Contraponto/Centro Internacional Celso Furtado, 2011.

LEWIS, W.A. Economic development with unlimited supplies of labour. Manchester School, v. 22, n. 2, p. 139-191, 1954.

LEWIS, W.A. The Dual Economy Revisited. Manchester School, v. 47, n. 3, p. 211-229, 1979.

LEWIS, W.A. Development Economics in the 1950s. In: Meier, G.M.; Seers, D. (eds). Pioneers in Development. Oxford: Oxford University Press, 1984, p. 121-137.

LIPPIT, V.D. The concept of the surplus in economic development. Review of Radical Political Economics, New York, v.17, n. 1-2, p. 1-19, 1985.

PERROUX, F. Pouvoir et économie. Paris: Bordas, 1973.

PINTO, A. Naturaleza e implicaciones de la heterogeneidad estructural de la América Latina. El Trimestre Económico, México, v. 37, n. 145(1), p. 83-100, 1970.

PREBISCH, R. Capitalismo Periférico: crisis y transformación. México: Fondo de Cultura Económica, 1981.

SANTARCÁNGELO, J.E. e BORRONI, C. El concepto de excedente en la toría marxista: debates, rupturas y perspectivas. Cuadernos de Economia, Bogotá, v. 31, n. 56, p. 1-20, 2012.

SUNKEL, O. La dependencia y la heterogeneidad estructural. El Trimestre Económico, México, v. 45 , n. 177(1), p. 3-20, 1978.

SUNNA, C. Dual Development Models in historical perspective. In: SUNNA, C.; GUALERZI, D. Development Economics in the Twenty-First Century. London: Routledge, 2016, p. 71-87. 
SZMRECSÁNYI, T. Celso Furtado. Estudos Avançados, São Paulo, v. 15, n. 43, p. 347-362, 2001.

SZMRECSÁNYI, T. Cinquentenário de A Economia Brasileira de Celso Furtado. Boletim Informativo da ABPHE, p. 1-2, dez. 2003.

TAVARES, M.C. Ciclo e Crise: o movimento recente da industrialização brasileira. 1978. $196 \mathrm{f}$. Tese (Professor Titular) - FEA-UFRJ, Rio de Janeiro, 1978.

TIGNOR, R.L. Arthur Lewis and the Birth of Development Economics. Princeton: Princeton University Press, 2006.

VERSIANI, F. R. Trabalho livre, trabalho escravo, trabalho excedente: mão de obra na Formação Econômica do Brasil. In: COELHO, F. S.; GRANZIERA, R. G. Celso Furtado e a Formação Econômica do Brasil. São Paulo: Atlas, 2009, p. 172-185.

\section{Sobre os autores}

\section{RenataBianconi-renatab@rocketmail.com}

Universidade Federal de São Paulo, Osasco, São Paulo, Brasil. Universidade Estadual de Campinas, Campinas, São Paulo, Brasil.

ORCID: https://orcid.org/0000-0002-4023-6830.

Mauricio C.Coutinho-coutinho@unicamp.br

Universidade Estadual de Campinas, Campinas, São Paulo.

ORCID: https://orcid.org/0000-0002-1253-8567.

Uma versão preliminar do presente trabalho foi apresentada na VI Conferência da Associação Latino-americana de História do Pensamento Econômico (ALAHPE), Bogotá, 2017. Os autores agradecem os comentários recebidos na ocasião. Renata Bianconi agradece o apoio financeiro da FAPESP e da CAPES, concedido por meio do processo nº 2014/26062-5, Fundação de Amparo à Pesquisa do Estado de São Paulo (FAPESP), e exime estas instituições de qualquer responsabilidade por hipóteses e conclusões expressas neste artigo.

\section{Sobre 0 artigo}

Recebido em 28 de março de 2019. Aprovado em 04 de outubro de 2019. 